\title{
RANCANGAN VIDEO IKLAN PADA PERGURUAN TINGGI RAHARJA SEBAGAI SARANA MEDIA PROMOSI
}

\author{
Giandari Maulani ${ }^{1}$ \\ Siti Aisah Febriani ${ }^{2}$ \\ Restu Amalia ${ }^{3}$ \\ Dosen STMIK Raharja ${ }^{1}$ \\ STMIK Raharja Jurusan Teknik Informatika ${ }^{2,3}$ \\ Jl. Jendral Sudirman No. 40, Modernland, Tangerang \\ E-mail: giandari@ raharja.info ${ }^{1}$, aisah.febriani@ raharja.info ${ }^{2}$, restu@ raharja.info $^{3}$
}

\begin{abstract}
ABSTRAK
Saat ini salah satu cara yang paling tepat untuk menyampaikan informasi adalah dalam bentuk audio maupun visual. Video iklan merupakan saah satu media informasi dan promosi berupa visualisai untuk mengenali suatu lembaga perusahaan dan instansi. Perguruan Tinggi Raharja merupakan salah satu instansi swasta yang bergerak dalam bidang pendidikan. Sarana yang tepat untuk mempromosikan nya yaitu dengan pembuatan video iklan pada Perguruan Tinggi Raharja. Video iklan ini bertujuan untuk mempromosikan dan menginformasikan Perguruan Tinggi Raharja kepada masyarakat. Dengan video iklan ini di harapkan dapat sebagai alat promosi dan informasi sekaligus sebagai dokumentasi. Rumusan masalah dalam video ini adalah bagaimana video iklan ini menjadi daya tarik tersendiri pada masyarakat. Manfaat dari pembuatan video iklan ini adalah sebagai sarana media promosi dan informasi kepada masyarakat dan memberi nilai tambah pada Perguruan Tinggi Raharja. Metode dalam penelitian ini menggunakan metode, observasi, wawancara, perancangan dan implementasi. Hasil penelitian ini berupa video iklan yang berisi informasi-informasi yang disusun dan dihubungkan satu dengan yang lain menjadi video visual, sehingga masyarakat dapat mengenal Perguruan Tinggi Raharja
\end{abstract}

Kata kunci : Video, Promosi, Informasi

\begin{abstract}
Now one of the ways most appropriate for information was in the form of audio and visual. Video advertising is one of the media information and promotion of visualisai to recognize an institution company and agencies. College raharja is one of private institutions which are engaged in education. A means of proper to promote his namely by making video advertising on college raharja.This commercial video aimed to promote and informs college raharja to the community. With this video commercial in hope will be as a means of promotion and information as well as documentation. Synthesis a problem in this video is how video this commercial be a special attraction to the community. The benefit of video advertising the manufacture of this is media as a means of promotion and information to the public and give added value to college raharja. Methods in this research using methods, observation, interview, design and implementation.This research result of video ads contains informasi-informasi developed and connected with each other being visual video, so people can know college raharja.
\end{abstract}

Keywords : Video, Promotion, Information

Vol.3 No.2 - Agustus 2017 


\section{PENDAHULUAN}

Seiring berkembangnya kemajuan teknologi multimedia sangat berpengaruh dalam media promosi. Salah satu kemampuan multimedia yaitu menyimpan dan mengolah gambar digital dan jutaan warna dengan resolusi tinggi serta memproduksi suara maupun video kedalam bentuk digital. Multimedia merupakan konsep dan teknologi dari unsur-unsur gambar, suara, animasi serta video disatukan didalam komputer untuk disimpan, diproses dan disajikan guna membentuk interaktif yang sangat inovatif antara komputer dengan user. Teknologi multimedia merupakan perpaduan antara teknologi komputer baik perangkat keras maupun perangkat lunak. Perkembangan multimedia dan pemanfaatan multimedia banyak digunakan dalam aspek apapun.

Penerapan multimedia dalam dunia pendidikan salah satunya dengan cara membuat iklan atau promosi berupa video. Video iklan terdiri dalam bentuk text, gambar, suara, dan video. Video iklan dibuat dengan tujuan menyampaikan informasi kepada masyarakat. Penelitian ini bertujuan sebagai kebutuhan promosi dalam dunia pendidikan, khususnya pada Perguruan Tinggi Raharja yang saat ini membutuhkan media promosi dalam bentuk iklan. Dalam pembutan video iklan ini sangat memperhatikan segi teknisnya dalam menggunakan aplikasi sesuai standart dan hadware yang mencukupi untuk menjalankan aplikasi tersebut. Pembuatan video iklan ini juga memperhatikan beberapa teknik seperti, camera angle, frame size. Pada teknik framing size ini atau teknik framing dalam pembuatan video iklan akan mempermudah pengambilan gambar dan menghemat biaya produksi, teknik ini hanya memerlukan tripod sebagai media dalam teknik framing.

Dengan biaya yang terjangkau dalam pembuatan video iklan ini diharapkan dapat menyampaikan informasi keseluruhan kepada masyarkat mengenai Perguruan Tinggi Raharja.

\section{PERMASALAHAN}

Sebelumnya penyampaian informasi tentang Perguruan Tinggi Raharja masih dengan cara manual yaitu dengan bekerja sama dengan sekolah sekolah untuk menyampaikan informasi tentang Perguruan Tinggi Raharja. Dalam permasalahan ini menyampaikan tentang cara yang tepat untuk menyampaikan informasi tentang Perguruan Tinggi Raharja. Cara yang tepat yaitu dengan menggunakan media promosi video iklan sebagai tempat untuk penyampaian informasi.

Dalam media promosi video iklan ini, akan menyampaikan berbagai informasi tentang Perguruan Tinggi Raharja, dalam penyampaian informasinya akan dibahas pengenalan singkat tentang jurusan dan konsentrasinya, media promosi iklan ini juga menyampaikan fasilitas dan keunggulan yang ada pada Perguruan Tinggi Raharja.

Rumusan masalah dalam penelitian ini adalah bagaimana cara yang tepat untuk menyampaikan informasi pada Perguruan Tinggi Raharja dengan menggunakan media promosi video iklan sebagai alat promosinya. Berdasarkan rumusan masalah yang telah di identifikasi maka tujuan yang ingin dihasilkan adalah mennyampaikan informasi secara jelas melalui video agar mudah dipahami oleh masyarakat.

\section{LITERATURE REVIEW}

Literature Review bisa di katakan Penelitian sebelumnya yaitu sebagai landasan acuan untuk bahan penelitian, yang berisi uraian teori-teori. Yang dilakukan dengan cara membaca, dan meriview dari berbagai macam sumber. Banyak penelitian yang sebelumnya dilakukan mengenai Rancangan Video Iklan Sebagai Sarana Media Promosi. Dalam upaya pembuatan video iklan ini 
perlu dilakukan studi pustaka sebagai salah satu dari penerapan metode penelitian yang akan dilakukan. Berikut ini adalah 10 referensi yang telah dilakukan dan memiliki kolerasi yang searah dengan penelitian yang akan dibahas dalam Jurnal ini diantaranya :

1. Penelitian yang dilakukan oleh Tyas Ajeng Nastiti, Nugrahadi Ramadhani, S.Sn., Mt pada tahun 2013 penelitian ini berjudul "Perancangan Video Promosi Surabaya Berupa TVC Sebagai Media Promosi Kota Surabaya Dengan Mengangkat Pencitraan Sparkling Surabaya". Potensi kota Surabaya tersebar diberbagai wilayah Surabaya. Sejak tahun 2010, sudah ada program pemerin yang digerakkan Dinas Pariwisata untuk mempromosikan daerah wisata di kota Surabaya. Seperti fasilitas Surabaya Heritage Track yang mengajak wisatawan untuk mengelilingi wilayah wisata di kota Surabaya seperti House of Sampoerna, Taman Budaya Cak Durasim, Monumen Pahlawan, Balai Pemuda, dan wisata religi Hong Ang Kiong. Namun demikian program Surabaya Heritage Track belum mampu mendobrak peningkatan kunjungan wisnu dan wisman ke wilayah wisata Surabaya. Beberapa wilayah wisata di Surabaya yang paling banyak dikunjungi hanya terpusat pada satu wilayah wisata dan kebanyakan wisnu dan wisman kurang mengetahui potensi wisata kota Surabaya yang lainnya

2. Penelitian yang dilakukan oleh Dias Hidayati pada tahun 2010 penelitian ini berjudul "Pembuatan Video Profile Istana Mangkunegaraan Surakarta Berbasis Multimedia". pembuatan video profil ini untuk memperkenalkan Istana Mangkunegaran Surakarta kepada masyarakat, agar masyarakat lebih mudah mengenal Istana Mangkunegaran Surakarta. Manfaat pembuatan video profil ini digunakan sebagai media promosi dan sebagai media dokumentasi. Metode ini menggunakan beberapa penelitian adalah Pustaka, Observasi, Wawancara, Analisis, Perancangan, Pengambilan gambar, Capturing, Editing, Perekaman suara dan Implementasi. Pembuatan video profil ini menggunakan komputer berbasis multimedia sebagai media promosi Istana Mangkunegaran Surakarta.

3. Penelitian yang dilakukan oleh Novan Andre Prastyo pada tahun 2010 penelitian ini berjudul "Pembuatan Video Profile Tiga Dimensi (3D) Sentra Ponsel Kudus". pembuatan video profil tiga dimensi (3D) ini adalah untuk memperkenalkan serta meningkatkan citra baik Sentra Ponsel kepada masyarakat. Manfaat pembuatan video profil tiga dimensi (3D) ini adalah dapat memanfaatkan hasil dari pembuatan video profile sebagai media penyampaian informasi dan promosi Sentra Ponsel kepada masyarakat umum. Dalam proses pembuatan Video Profile Tiga Dimensi (3D) Sentra Ponsel Kudus, ini menggunakan metode kepustakaan, observasi, wawancara, perancangan dan pembuatan dengan menggunakan 3D MAX 2011, konfigurasi sistem, pemberian animasi menggunakan Photoshop, Coreldraw ujicoba video profile, implementasi.

4. Penelitian yang dilakukan oleh pada tahun 2014 penelitian ini berjudul "Pembuatan Video Profil Sekolah Menengah Pertama Negeri 4 Polokarto Kabupaten Sukoharjo Dengan Menggunakan Multimedia". Penelitian ini bertujuan untuk sebagai alat promosi dan informasi kepada masyarakat sekaligus sebagai dokumentasi. Rumusan masalah dari penelitian ini adalah bagaimana membuat video profil Sekolah Menengah Menengah Pertama Negeri 4 Polokarto dengan menggunakan komputer multimedia. Penelitian ini dibatasi pada pembuatan video profil di SMP N 4 Polokarto Sukoharjo dengan menggunakan komputer multimedia.

5. Penelitian yang dilakukan oleh Alfa Maulana pada tahun 2012 penelitian ini berjudul "Pembuatan Video Company Profile Berbasis Multimedia Pada Sekolah Menengah Kejuruan Kosgoro 1 Sragen". Dengan menerapkan sistem Virtual Account di beberapa 
sekolah yang menjadi target market, maka Bank Danamon disamping dapat membantu manajemen sekolah meningkatkan produktivitasnya juga sekaligus dapat memperluas pangsa pasarnya di dalam persaingan bisnis perbankan. Penulis ingin mengetahui peran dari sistem Virtual Account itu sendiri dalam membantu pihak manajemen sekolah meningkatkan produktivitasnya melalui rekonsiliasi pembayaran uang sekolah. Dimana dengan menerapkan sistem tersebut maka pembuatan rekonsiliasi tersebut akan terintegrasi baik menjadi sebuah proses yang lebih cepat dalam hal penyajian dan meminimalisir faktor human-error.

6. Penelitian yang dilakukan oleh Fabricio Benevenuto pada tahun 2008 penelitian ini berjudul "Understanding video interactions in youtube"This paper seeks understanding the user behavior in a social network created essentially by video interactions. We present a characterization of a social network created by the video interactions among users on YouTube, a popular social networking video sharing system. Our results uncover typical user behavioral patterns as well as show evidences of anti-social behavior such as selfpromotion and other types of content pollution.

Setelah melakukan tinjauan dari enam literature review yang ada, telah banyak penelitian mengenai pembuatan video promosi untuk sebuah instansi. Oleh karna itu video ini dibuat untuk mempromosikan lebih luas Perguruan Tinggi Raharja kepada masyarakat. Oleh karena itu penulis membahas hal "Rancangan Video Iklan Pada Perguruan Tinggi Raharja Sebagai Sarana Media Promosi" agar dapat meningkatkan promosi terhadap Perguruan Tinggi Raharja.

\section{PEMECAHAN MASALAH}

Untuk mengatasi berbagai masalah tersebut, maka diperlukan sebuah media promosi yang efektif dan efisien dalam mempromosikan Perguruan Tinggi Raharja. Dari rumusan masalah tersebut menghasilkan satu pemecahan masalah yaitu dengan adanya Video iklan promosi ini diharapkan masyarakat dapat mengenal lebih luar tentang Perguruan Tinggi Raharja dan memudahkan masyarakat mengetahui dengan progam studi beserta jurusan yang ada pada Perguruan Tinggi Raharja. Didalam video promosi ini akan menjelaskan berbagai program studi, jurusan, konsentrasi, serta akreditasi beserta fasilitas dan keuungulannya. Dengan demikian, masyarakat akan lebih mudah untuk mengetahuinya. Pada pemecahan masalah menggunakan mind mapping dan Analisa SWOT :

Mind Mapping

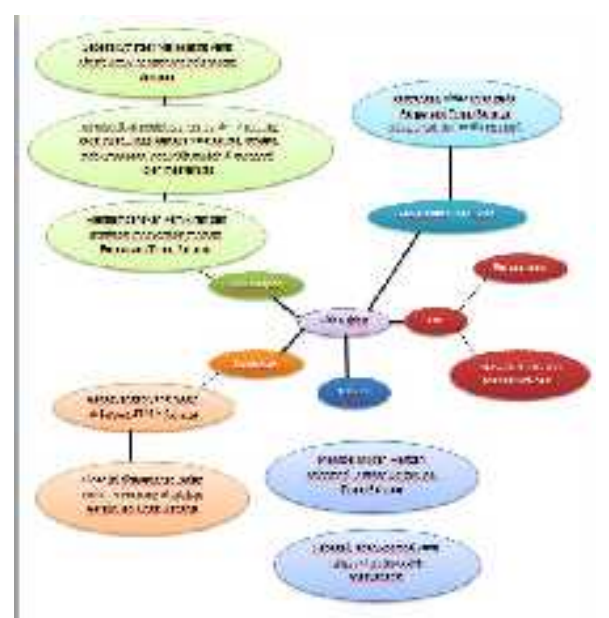

Gambar 1. Mind Mapping 
Rancangan Video Iklan pada Perguruan Tinggi Raharja Sebagai Sarana Media Promosi

Mind Mapping adalah cara paling efektif dan efisien untuk memasukan, menyimpan, dan mengeluarkan data dari dan ke otak. Sistem ini bekerja sesuai cara kerja alami otak kita, sehingga dapat mengoptimalkan seluruh potensi dan kapasitas otak manusia ([Caroline Edward, 2005: ${ }^{64]}$. Ditinjau dari segi waktu mind mapping juga dapat mengefisienkan penggunaan waktu dalam mempelajari suatu informasi. Dalam Hal ini disebabkan karena metode yang disajikan merupakan gambaran menyeluruh atas suatu hal, dalam waktu yang relatif singkat.

Dengan adanya mind mapping ini dapat di jelaskan kelebihan dari video iklan yaitu sebagai media Promosi Perguruan Tinggi Raharja, untuk strategi marketing yang cukup efektif, serta memberikan penjelasan secara detail tentang Perguruan Tinggi Raharja yang informasinya sangat akurat, dan inovatif. Video iklan ini, dikemas sangat kreatif, tidak monoton, dan lebih mudah di mengerti oleh pribadi Raharja ataupun masyarakat. Sehingga dapat mengembangkan pemikiran dan pedapat tentang Perguruan Tinggi Raharja.

Pada metode Mind Mapping ini menghasilkan sebagai berikut yaituvideo iklan yang berisi penjelasan tentang Perguruan Tinggi Raharja, sistem yang berjalan pada Perguruan Tinggi Raharja, dengan menggunakan metode iLearning pada pebelajaran mahasiswanya serta penilaaian yang menggunakan defisiasi. Perguruan Tinggi Raharja sudah menggunakan sistem keseluruhan secara online. Dalam video iklan promosi ini akan menjelaskan beberapa keunggulan serta prestasi yang sudah di raih oleh Perguruan Tinggi Raharja. Tujuan dari video iklan promosi ini, Mempermudah Pribadi Raharja ataupun masyarakat Mencari Informasi Tentang Perguruan Tinggi Raharja, dan dapat mudah diterima oleh semua orang. Adapun kekurangan dari video Iklan promosi ini yaitu, penayangan yang di tayangkan haya di sekitar raharja saja, dan pada event-event tertentu, serta hanya dimasukan ke dalam media social youtube yang hanya bisa di search saja.

\section{SWOT}

Tabel 1. Analisa SWOT

\begin{tabular}{|c|c|c|}
\hline & Strenght (Kekuatan) & Weakness (Kelemahan) \\
\hline Faktor Internal & $\begin{array}{l}\text { 1. Tidak perlu membuat } \\
\text { Brosur ataupun Spanduk } \\
\text { 2. Video Iklan ini dapat Di } \\
\text { lihat melalui Youtube } \\
\text { 3. Menyebarkan Informasi } \\
\text { Kegiatan Belajar } \\
\text { mengajar dan jurusan } \\
\text { yang ada di Perguruan } \\
\text { Tinggi Raharja dengan } \\
\text { data yang akurat. }\end{array}$ & $\begin{array}{l}\text { 1. Video Ini hanya di } \\
\text { tampilkan pada event- } \\
\text { event Perguruan Tinggi } \\
\text { Raharja saja dan di } \\
\text { wilayah Kampus } \\
\text { Perguruan Tinggi Raharja } \\
\text { 2. Sudah di upload di media } \\
\text { social youtube, dan } \\
\text { belum banyak yang } \\
\text { mengetahui, jadi perlu di } \\
\text { informasikan. }\end{array}$ \\
\hline
\end{tabular}

Vol.3 No.2 - Agustus 2017 


\begin{tabular}{|c|c|c|}
\hline \multicolumn{3}{|l|}{ Faktor Eksternal } \\
\hline Opportunity (Peluang) & Strategy SO & Strategy WO \\
\hline $\begin{array}{l}\text { 1. Meningkatkan Strategi } \\
\text { Media Marketing } \\
\text { Perguruan Tinggi Raharja } \\
\text { 2. Iklan dapat diterima oleh } \\
\text { oleh semua orang } \\
\text { 3. Ekonomis untuk segi } \\
\text { Promosi }\end{array}$ & $\begin{array}{l}\text { 1. Dengan memanfaatkan } \\
\text { kekuatan perusahaan } \\
\text { untuk memaksimalkan } \\
\text { peluang yang dipunya } \\
\text { oleh perusahaan } \\
\text { 2. Strategi yang didapatkan } \\
\text { adalah, dengan konsep } \\
\text { video yang sangat } \\
\text { modern maka akan } \\
\text { menambah daya traik } \\
\text { tersendiri }\end{array}$ & $\begin{array}{l}\text { 1. meminimalisirkan } \\
\text { kelemahan yang dimiliki } \\
\text { oleh perusahaan untuk } \\
\text { dapat memaksimalkan } \\
\text { banyak peluang yang bisa } \\
\text { didapat oleh perusahaan }\end{array}$ \\
\hline Threat (Ancaman) & Strategi ST & Strategi WT \\
\hline $\begin{array}{l}\text { 1. Belum banyak yang } \\
\text { mengetahui Video Iklan } \\
\text { Promosi ini sudah di } \\
\text { Akses pada Media Sosial } \\
\text { Youtube } \\
\text { 2. Tidak Dapat di akses bila } \\
\text { tidak ada jaringan } \\
\text { Internet } \\
\text { 3. Dan baru di tayangkan } \\
\text { sekitar Raharja saja }\end{array}$ & $\begin{array}{l}\text { 1. Strategi yang didapatkan } \\
\text { adalah memberikan } \\
\text { sosialisasi tentang } \\
\text { keunggulan dari video ini } \\
\text { sehingga menjadi daya } \\
\text { tarik tersendiri dalam } \\
\text { video promosi ini }\end{array}$ & $\begin{array}{l}\text { 1. dengan mengetahui } \\
\text { kelemahan yang dipunyai } \\
\text { oleh perusahaan untuk } \\
\text { dapat segera } \\
\text { meminimalisir ancaman } \\
\text { yang akan mengancam } \\
\text { perusahaan jika } \\
\text { kelemahan tidak segera } \\
\text { diatasi }\end{array}$ \\
\hline
\end{tabular}

SWOT digunakan untuk menilai kekuatan-kekuatan dan kelemahan-kelemahan dari sumber-sumber daya yang dimiliki perusahaan dan kesempatan-kesempatan eksternal dan tantangan-tantangan yang dihadapi ${ }^{([J o g i y a n t o, ~ 2005])}$.Pada pemecahan masalah menggunakan metode SWOT yang kemudian akan diaplikasikan untuk Rancangan Video Iklan Pada Perguruan Tinggi Raharja Sebagai Sarana Media Promosi pada Perguruan Tinggi Raharja.

Setelah membandingkan antara faktor eksternal peluang dan ancaman dengan faktor internal kekuatan dan kelemahan sehingga dari analisis tersebut dapat diambil suatu keputusan strategis suatu organisasi, yaitu sebagai berikut, Strategi SO diterapkan berdasarkan perbandingan antara strength (kekuatan) dan opportunity (peluang), yaitu dengan memanfaatkan kekuatan perusahaan untuk memaksimalkan peluang yang dipunya oleh perusahaan. Strategi yang didapatkan adalah, dengan konsep video yang sangat modern maka akan menambah daya traik tersendiri.Strategi ST diterapkan berdasarkan perbandingan antara strength (kekuatan) dan thread (ancaman), yaitu dengan memanfaatkan strategi kekuatan yang dipunyai oleh perusahaan untuk dapat meminimalisir ancaman yang ada bagi perusahaan. Strategi yang didapatkan adalah 
memberikan sosialisasi tentang keunggulan dari video ini sehingga menjadi daya tarik tersendiri dalam video promosi ini.

Strategi WO diterapkan berdasarkan perbandingan antara weakness (kelemahan) dan opportunity (peluang), yaitu dengan meminimalisirkan kelemahan yang dimiliki oleh perusahaan untuk dapat memaksimalkan banyak peluang yang bisa didapat oleh perusahaan. Strategi yang didapatkan adalah melakukan sosialisasi tentang Rancangan Video Iklan Pada Perguruan Tinggi Raharja Sebagai Sarana Media Promosi pada Perguruan Tinggi Raharja, kepada masyarakat.Strategi WT diterapkan berdasarkan perbandingan antara weakness (kelemahan) dan thread (ancaman), yaitu dengan mengetahui kelemahan yang dipunyai oleh perusahaan untuk dapat segera meminimalisir ancaman yang akan mengancam perusahaan jika kelemahan tidak segera diatasi.

\section{PROTOTYPE}

Prototyping merupakan salah satu metode pengembangan perangat lunak yang banyak digunakan. Dengan metode prototyping ini pengembang dan pelanggan dapatsaling berinteraksi selama proses pembuatan sistem. ([Wahyu Lukman Hakim, 2012:2]). Prototype memberikan pelayanan bagi pengembang saling berhubungan selama proses pembuatan, sehingga dapat dengan mudah menggambarkan sebuah video yang akan di buat. Pada prototype Rancangan Video Iklan Pada Perguruan Tinggi Raharja Sebagai Sarana Media Promosi pada Perguruan Tinggi Raharja berikut merupakan proses membuatVideo Iklan Pada Perguruan Tinggi Raharja Sebagai sarana Media Promosi.

1. Menentukan konsep dan menulis sinopsis dalam pembuatan video iklan ini

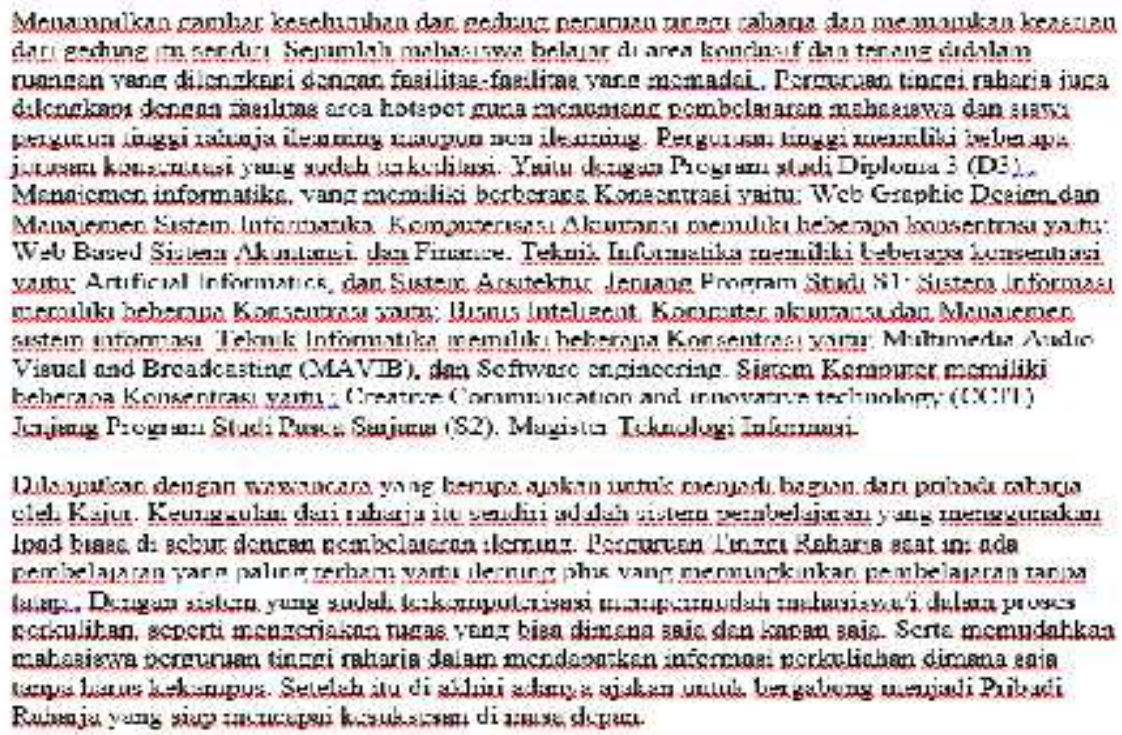

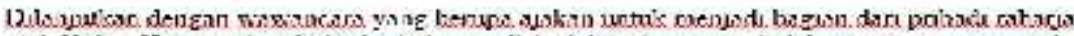

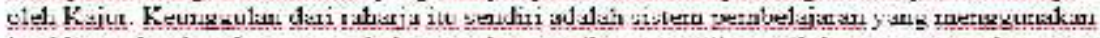

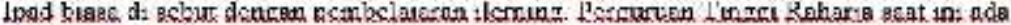

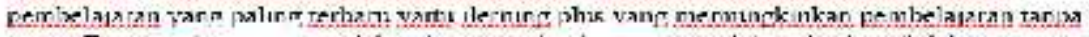

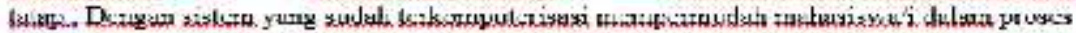

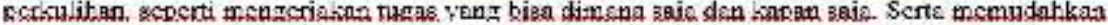

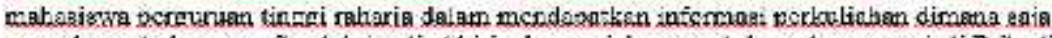

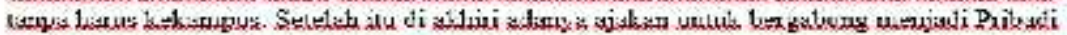

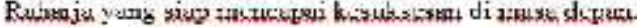

\section{Gambar 2. Prototype Isi sinopsis dari pembuatan video iklan}


2. Menyusun Narasi yang akan di dubing oleh dubber
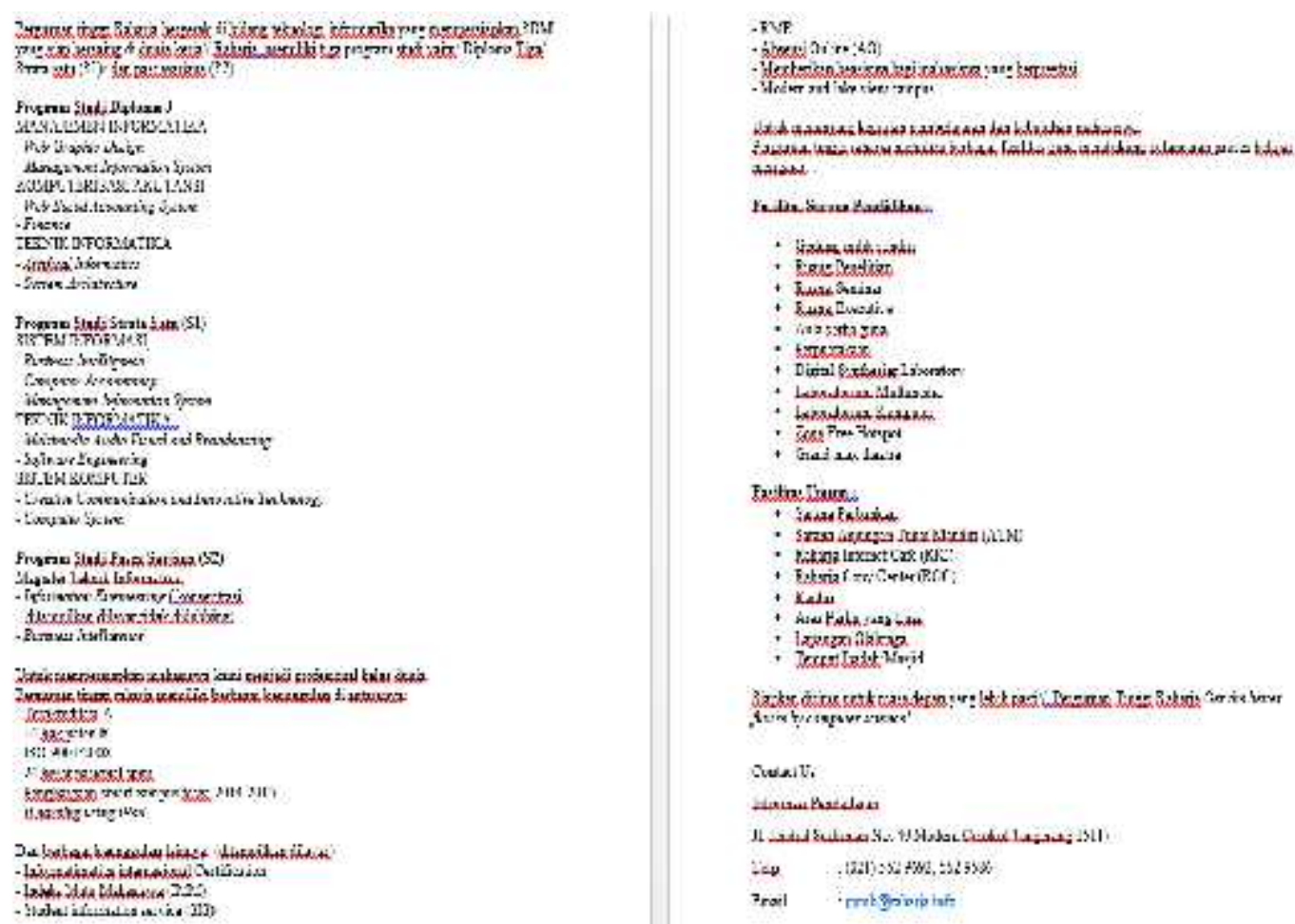

Gambar 3. Prototype Menyusun Narasi.

3. Menulis Script untuk menentukan pengambilan gambar

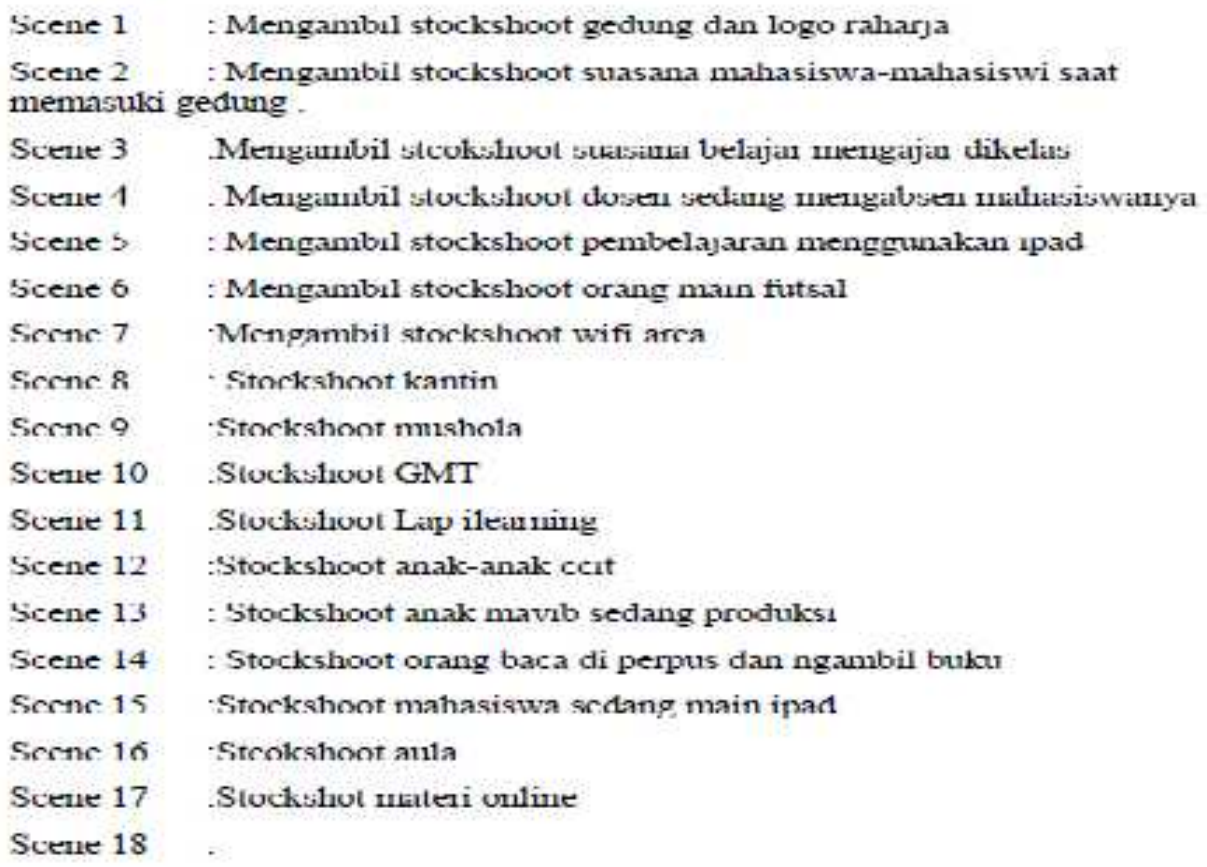

Gambar 4. Prototype Script mempermudah proses pengambilan gambar 
4. Proses Editing Video iklan

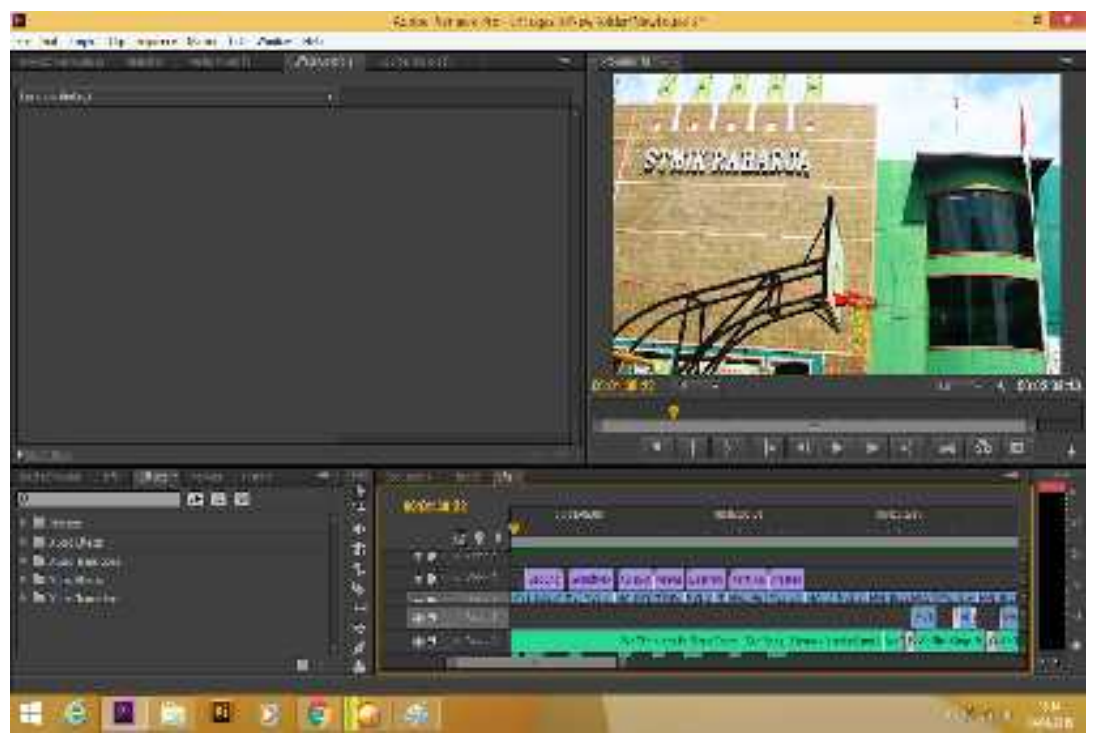

Gambar 5. Prototype Editing video menggunakan Adobe Premier

5. Tampilan Awal Video

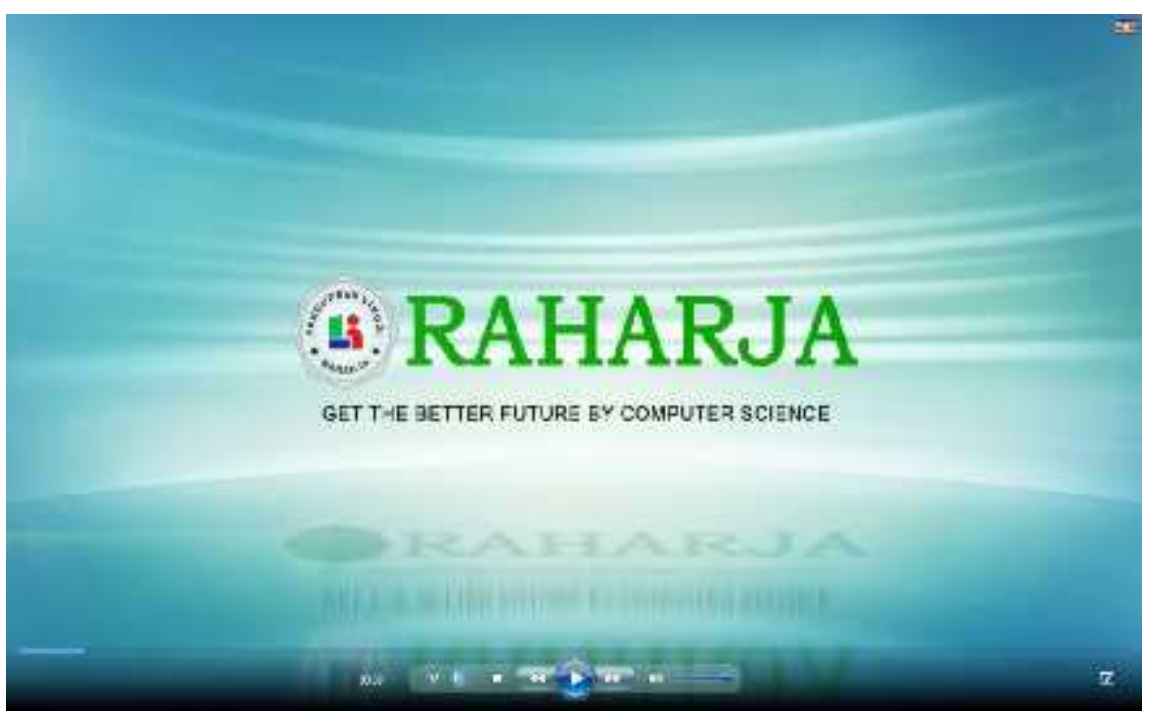

Gambar 6. PrototypeTampilan awal video 
6. Menampilkan Program Studi

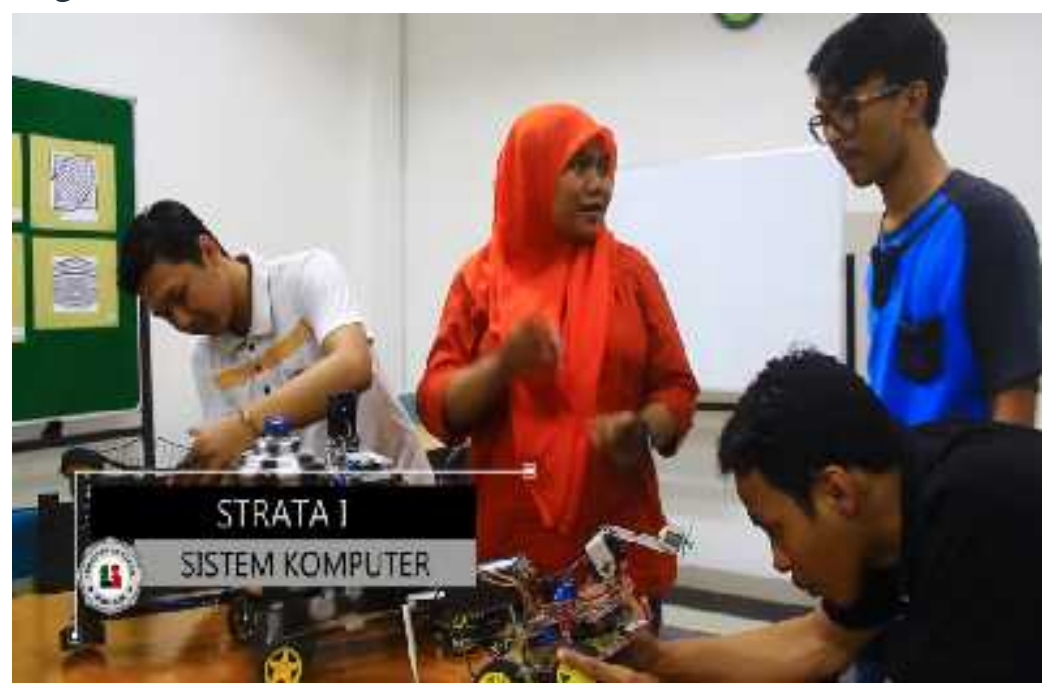

Gambar 7. Prototype Strata 1 Sistem Komuter

7. Program Studi Strata 2

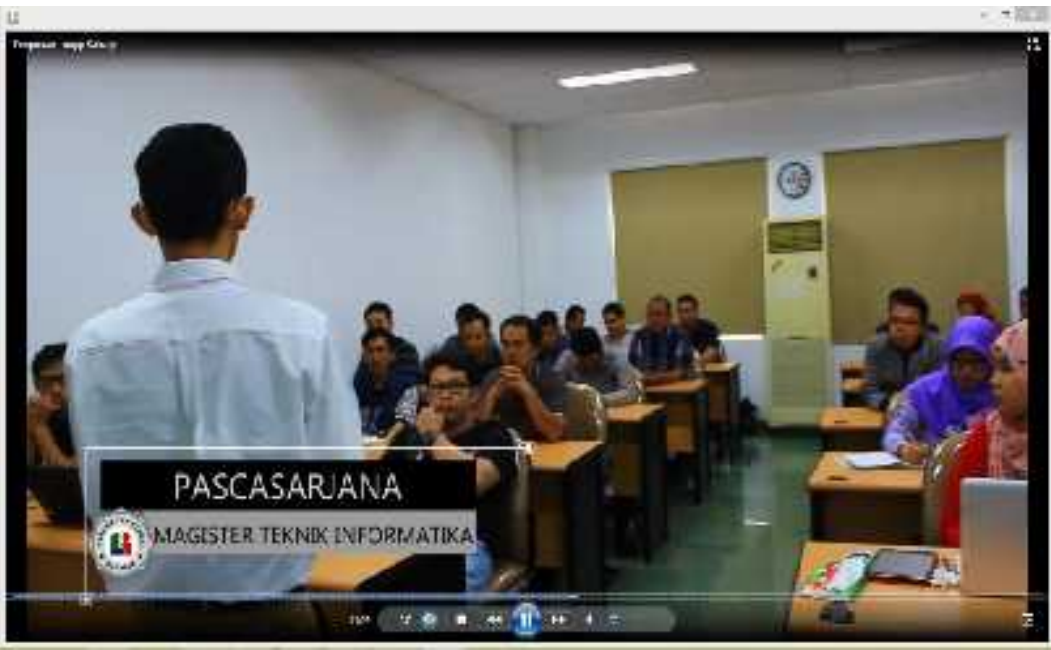

Gambar 8. Prototype Strata 2 Magister Teknik Informatika 
8. Hasil Akhir Video

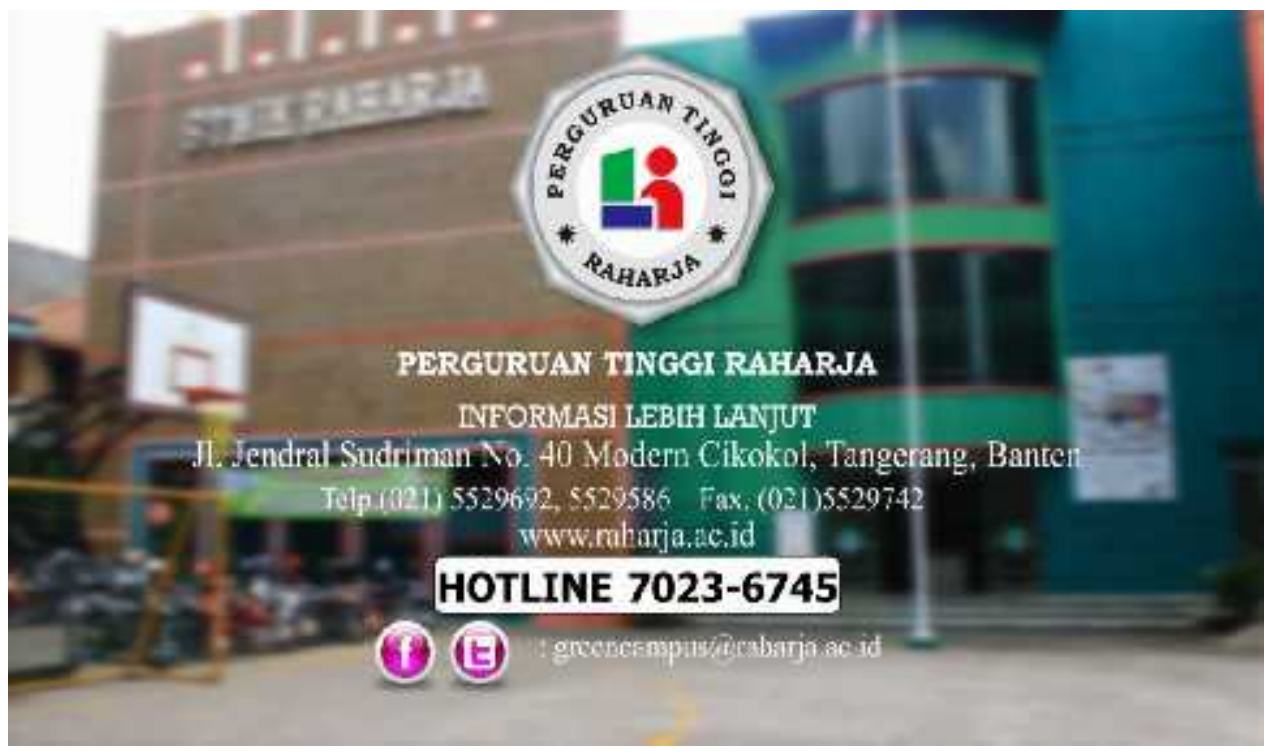

Gambar 9. Prototype Hasil Akhir Video

\section{KELEBIHAN VIDEO IKLAN}

Seperti yang sudah dijelaskan sebelumnya, video iklan atau video promosi ini merupakan alat strategi marketing yang efektif untuk pemasaran baik barang dan jasa. Terlebih lagi, video ini dapat Anda manfaatkan untuk memberikan penjelasan secara detail tentang Perguruan Tinggi Raharja yang inovatif, tidak monoton, dan lebih mudah dimengerti masyarakat

Ada juga kelebihan lainnya dari video iklan atau video promosi, yaitu seperti, mengembangkan pikiran dan pendapat masyarakat tentang Perguruan Tinggi Raharja, mengembangkan minat dan motivasi para masyarakat dan pribadi raharja untuk melakukan hal yang ada didalam video, memotivasi aktifitas sehari-hari, menjelaskan "hal" yang masih bersifat abstrak, dan memberikan gambaran pengalaman yang lebih real.

\section{KELEMAHAN VIDEO IKLAN}

Kelemahan dari video ini yaitu, penanyangannya masih disekitar Perguruan Tinggi Raharja dan setiap event-event yang ada di Perguruan Tinggi Raharja.

\section{KESIMPULAN}

Dengan demikian dapat disimpulkan, penelitian ini menggunakan metode mind mapping dan analisa SWOT. Penggunaan Metode ini sangat sesuai dengan kebutuhan pengembangan video iklan untuk memudahkan Perguruan Tinggi Raharja mempromosikan, menyebarkan informasi, yang dapat diterima oleh masyarakat ataupun calon mahasiswa baru yang ingin mengetahui lebih jelas lagi sistem belajar, jurusan, dan konsentarasi mereka. Dengan adanya Rancangan Video Iklan pada Perguruan Tinggi Raharja sebagai sarana media Promosi, diharapkan dapat meminimalisirkan pembuatan brosur, spanduk untuk mempromosikan. Video Iklan ini juga sudah di upload dalam media social youtube, agar masyarakat ataupun Pribadi 
Raharja mudah mendapatkan informasi dan mencarinya. Video iklan ini juga disajikan informasi yang tidak monoton, dan sangat akurat, cepat dan efesien sesuai dengan kebutuhan yang di analisa dengan menggunakan metode SWOT yang dapat meningkatkan mutu Perguruan Tinggi Raharja.

\section{DAFTAR PUSTAKA}

[1] Benevenuto. 2008. "Understanding video interactions in youtube". Brazil: Federal University of Minas Gerais. Vol. 2,ISSN: 9781605583037

[2] Crespi, Cherly (2012) "The value of studentcreated videos in the collage classroom - An exploratory study in marketing and acounting"

[3] Hakim, Wahyu Lukman . 2012. Pengertian Prototype. "https://www.scribd.com/doc/58298607/Pengertian-Prototype"

[4] Hidayati, Dias (2010). "Pembuatan Video Profile Istana Mangkunegaraan Surakarta Berbasis Multimedia” Universitas Surakarta, Vol 2 No 1

[5] Kusuma, Ferry Angga (2015). "Pengaruh Penggunaan Strategi Pembelajaran Mind Mapping Terhadap Hasil Belajar Matematika Siswa Kelas VII SMP Negeri Muara Beliti”

[6] Maulana, Alfa (2012) "Pembuatan Video Company Profile Berbasis Multimedia Pada SekolahMenengah Kejuruan Kosgoro 1 Sragen"

[7] Nasiti. Tyas Ajeng 2013. "Perancangan Video Promosi Surabaya Berupa TVC Sebagai Media Promosi Kota Surabaya Dengan Mengangkat Pencitraan Sparkling Surabaya" Kajian Pustaka.2012. Pengertian SWOT. "http://www.kajianpustaka.com/2013/03/strenghtsweakness-opportunities". 4 Febuari 2016. 